\title{
Utero-vaginal prolapse: A community study at Duradada, Lamjung, Nepal
}

\author{
Prabhat Adhikari \\ Institute of Medicine (IOM) \\ Tribhuvan University Teaching Hospital
}

\section{Dear Editor}

\section{Background}

Uterovaginal prolapse (UVP) defined as "protrusion of uterus and cervix along with vaginal wall below its normal level" is understood to be a common malady in Nepalese women. Basically, this problem is related to successive unattended vaginal birth at domiciliary setting, where women deliver themselves without any support or even minimal help rendered by female family members such as a mother-in-law or sister-in-law. Although many studies already exist to confirm its occurrence, this small community study in a remote part of the country, Duradada in Lamjung district, may serve as additional observational findings of uterovaginal prolapse occurring significantly in parturient women soon after delivery than those at an age in and around menopause.

\section{Methods}

We conducted a cross-sectional reproductive morbidity study in Duradada, Lamjung District of Nepal on 9-10 Dec 2006 (063/08/23-24).

\section{Result}

The study indicated a total number of 252 gynaecological cases out of which 20 (8\%) had major degrees of pelvic organ prolapse (POP) inclusive of a case of vault prolapse. All the cases were associated with cystocele and rectocele. One case had additional findings of enterocele. There was one case of procidentia (severe degree of POP where even the fundus of uterus, lies below the introitus). Of the 20 cases with POP, 6 (30\%) were unrelated to child birth, 2 developed the genital prolapse in post menopausal years and 4 during the perimenopausal period. Other $14 / 20(70 \%)$ cases were related mainly to childbirth. Of them, 12/14 were home delivery (self- 9 and assisted by mother-in-law -3); a delivery each with assistance of traditional birth attendant- 1 and doctor- 1 with limited puerperal rest. Mean age at menarche, marriage and menopause were 15.8, 15.05, 45.9 years respectively and mean parity was 5 . Prolapse occurred after lifting heavy loads soon after delivery within 11days (6); 1 month (4), 2 months (3) and 5months (1). This was soon followed by pregnancy and delivery as birth spacing was 1-2 years (8); >2-3years (4); >3-5 years (2); such that a 60 years old lady conferred having had four pregnancy and delivery with prolapse since first child-birth and was suffering with this problem for more than 20 years.

\section{Discussion}

In this respect the study describes problems of prolapse in rural Nepalese women where repeated child birth is identified as the cause of this condition although menopausal status and estrogen deficiency may be cited as next predisposing factor; UVP is regarded as annoying therefore concealed by women. There were many elderly women enduring prolapse for more than 20 years, and had not revealed the fact to anyone. A 60 year old woman managed to bear four children after having UVP since first child-birth and yet did not confide her misery to anyone. This inadvertently encourages the hiding tendency or reluctance of women to expose this condition of genital prolapse because of social taboos enhanced by economic barrier to attain surgical cure.

\section{Conclusion}

Prevention of genital prolapse can only be ascertained by improvised health education and health seeking behavior of rural Nepalese women, whatever is existent within the health facility with a word of advise to attended deliveries, birth spacing and puerperal rest.

\author{
Correspondence \\ Prabhat Adhikari \\ MBBS, Intern, Institute of Medicine (IOM) \\ Tribhuvan University Teaching Hospital \\ MD Resident in Medicine USA \\ prabhatadhikari@iom.edu.np
}

